\title{
PENGARUH REMINISCENCE GROUP THERAPY TERHADAP STATUS HARGA DIRI LANSIA POST POWER SYNDROME
}

\author{
Andi Nur Setyawati 1), Eny Sutria ${ }^{2), S y a m s i a h ~ R a u f ~}{ }^{2)}$, Nur Hidayah ${ }^{2)}$,Saleh Ridwan 3 ) \\ 1 Mahasiswa Jurusan Keperawatan Fakultas Kedokteran dan Ilmu Kesehatan UIN Alauddin Makassar \\ 2 Dosen Keperawatan Fakultas Kedokteran dan Ilmu Kesehatan UIN Alauddin Makassar \\ 3 Dosen Fakultas Syariah dan Hukum UIN Alauddin Makassar \\ Email : andinursetyawati@gmail.com
}

\begin{abstract}
Self-concept is closely related to one's self-esteem. Low self-esteem is a major problem for an elderly person who involves negative self-evaluation and is associated with feelings of weakness, helplessness, worthlessness and fear. The purpose of this study was to determine the effect of reminiscence group therapy on the self-esteem status of elderly post power syndrome. The research method used pre-experimental design with one group pretestposttest. Sampling uses purposive sampling method with a total sample of 11 elderly respondents who have retired with post power syndrome. The results showed that there was a significant effect of reminiscence group therapy on the self-esteem status of elderly post power syndrome with a $P$ value $=0.001$ or $P<0.05)$. Conclusion: There is an effect on the implementation of reminiscence group therapy on the self-esteem status of post power syndrome elderly in working area Primery Health Care Samata. Expected this research can be used as a reference material for educational institutions and health service institution to the implementation of reminiscence group therapy.
\end{abstract}

Keywords: Reminiscence Group Therapy, Elderly, Self Esteem, Post Power Syndrome.

\section{PENDAHULUAN}

Pada hakikatnya, orang yang akan bekerja akan tiba pada masa dimana individu tersebut harus berhenti dari pekerjaanya. Perubahan status dari bekerja menjadi tidak bekerja dapat menjadi faktor terjadinya stressor psikologis pada lansia yang dapat berkembang menjadi konsep diri yang negatif yakni perasaan tidak berharga (Syarniah, 2010). Havighurst dalam Azizah (2011) menyebutkan bahwa salah satu tugas perkembangan lansia`adalah menyesuaikan diri terhadap masa pensiun dan penurunan pendapatan. Setelah para usia lanjut tersebut pensiun, mereka akan merasa kehilangan peran,identitas,serta semua status yang berpengaruh terhadap konsep dirinya (Nurhayati, 2015).
Penelitian yang dilakukan oleh Holmes dan Rahe tahun 2006 mengungkapkan bahwa pensiun menempati peringkat 10 besar dalam penyebab depresi. Pihak yang paling takut dalam menghadapi pensiun adalah Pegawai Negeri Sipil (PNS), karena PNS yang telah habis masa tugasnya akan mengalami mental shock .Mental shock tersebut disebabkan karena mereka telah merasa kehilangan identitas dan status sosialnya yang selama ini disandangnya. Beberapa studi secara konsisten melaporkan bahwa antara 30$33 \%$ pensiunan menyatakan berbagai perasaan negatif saat menghadapi masa pensiun. Para pegawai yang telah habis masa purna tugasnya atau pensiun akan mengalami mental shock karena 
menjelang akhir masa kerja aktivitasnya pun menjadi berkurang dan juga setelah menghadapi pensiun maka semua kekuasaan dan kekuatan yang pernah dimiliki sebelumnya seketika akan dilepas dan diberikan kepada orang lain. Salah satu hal inilah yang dapat memicu munculnya post power syndrome dikalangan pegawai yang berada dibawa naungan pemerintah ( Yuliasari, 2006).

Post-power syndrome merupakan sekumpulan gejala yang muncul setelah seseorang melepas jabatan ataupun terlepas dari pekerjaannya. Perubahanperubahan psikis yang muncul pada individu dengan post power syndrome adalah individu akan lebih mudah stress, depresi, putus asa, ketergantungan, merasa kekosongan, merasa tidak bahagia serta kehilangan harga diri yang rendah merupakan masalah utama bagi seorang lansia yang melibatkan evaluasi diri negatif dan berhubungan dengan perasaan lemah, tak berdaya, tidak berharga dan ketakutan. Penelitian yang dilakukan oleh Butler (2010), terkait dengan reminiscence group therapy terhadap harga diri lansia,hasilnya menjelaskan bahwa terapi ini dapat digunakan untuk meningkatkan harga diri lansia serta berguna dalam mempromosikan kesehatan psikososial pada lanjut usia.

Reminiscence group therapy atau terapi kenangan merupakan salah satu jenis terapi dengan pendekatan perilaku dan kognitif yang dirancang khusus untuk meningkatkan status kesehatan mental pada lansia dengan menggunakan memori tentang hal-hal yang menyenangkan bagi lansia untuk memelihara kesehatan mental dan meningkatkan kualitas hidup (Chen, $\mathrm{Li}, \& \mathrm{Li}, 2012)$. Menurut Fontaine dan Faltcher tahun 1995 terapi ini bertujuan untuk meningkatkan harga diri, membantu individu mencapai kesadaran diri, memahami diri, beradaptasi dengan stress, serta klien mampu melihat dirinya dalam konteks budaya dan sejarah (Banon, 2011).

\section{BAHAN DAN METODE}

Penelitian ini menggunakan metode kuantitatif dengan desain penelitian pre eksperimental dengan pendekatan one group pre and post test design. Populasi dalam penelitian ini adalah seluruh lansia yang telah pensiun di Perumahan Pepabri Kelurahan Samata yang berjumlah 42 orang. Sampel dalam penelitian adalah 12 orang lansia yang berada di perumahan pepabri kelurahan samata. Teknik pengambilan sampel dalam penelitian ini adalah purposive sampling yaitu mengambil sampel yang sesuai dengan kriteria inklusi dan eksklusi berjumlah 12 orang.

Dalam penelitian ini instrumen yang digunakan berupa lembar screening gejala post power syndrome dan kuesioner baku dari Rosenberg Self Esteem (RSES) yang terdiri dari 10 item pertanyaan. Uji statistik yang digunakan adalah $U j i$ Wilcoxon Test.

\section{HASIL}

\section{a. Analisis Univariat}

\section{1) Gambaran Karakteristik Responden}

Responden pada penelitian ini adalah 12 orang lansia yang telah pensiun dan berada di Perumahan Pepabri Kelurahan Samata. 
Tabel 1. Distribusi Frekuensi Responden Berdasarkan Usia, Jenis Kelamin,Pendidikan Terakhir, Status Pernikahan,Sumber Penghasilan, Dan Pekerjaan Terakhir .

\begin{tabular}{|c|c|c|}
\hline \multirow[t]{2}{*}{ Variabel } & \multicolumn{2}{|c|}{$\begin{array}{l}\text { Kelompok } \\
\text { Responden }\end{array}$} \\
\hline & Jumlah (n) & $\begin{array}{c}\text { Presentasi } \\
(\%)\end{array}$ \\
\hline \multicolumn{3}{|l|}{ Usia } \\
\hline Usia 61 & 2 & $18,2 \%$ \\
\hline Tahun & 3 & $27,3 \%$ \\
\hline Usia 62 tahun & 6 & $54,5 \%$ \\
\hline \multicolumn{3}{|l|}{ Usia 65 tahun } \\
\hline Total & $\underline{11}$ & $100,0 \%$ \\
\hline \multicolumn{3}{|l|}{ Jenis } \\
\hline \multicolumn{3}{|l|}{ Kelamin } \\
\hline Laki-Laki & 5 & $45,5 \%$ \\
\hline Perempuan & $\underline{6}$ & $54,5 \%$ \\
\hline Total & 11 & $100,0 \%$ \\
\hline \multicolumn{3}{|l|}{ Tingkat } \\
\hline \multicolumn{3}{|l|}{ Pendidikan } \\
\hline SMU & 2 & $18,2 \%$ \\
\hline Perguruan & 9 & $81,8 \%$ \\
\hline \multicolumn{3}{|l|}{ Tinggi } \\
\hline Total & $\underline{11}$ & $100,0 \%$ \\
\hline \multicolumn{3}{|l|}{ Status } \\
\hline \multicolumn{3}{|l|}{ Pernikahan } \\
\hline Menikah & $\underline{11}$ & $100,0 \%$ \\
\hline Total & 11 & $100,0 \%$ \\
\hline \multicolumn{3}{|l|}{ Sumber } \\
\hline \multicolumn{3}{|l|}{ Penghasilan } \\
\hline Pensiun & $\underline{11}$ & $100,0 \%$ \\
\hline Total & 11 & $100,0 \%$ \\
\hline \multicolumn{3}{|l|}{ Pengalaman } \\
\hline \multicolumn{3}{|l|}{ Kerja } \\
\hline PNS & 10 & $90,9 \%$ \\
\hline TNI & $\underline{1}$ & $\underline{9,1 \%}$ \\
\hline Total & 11 & $91,6 \%$ \\
\hline
\end{tabular}

Sumber : Data Primer, 2018.

Berdasarkan tabel 4.1 distribusi frekuensi usia responden menunjukan bahwa dari 11 responden usia terbanyak yang menjadi responden adalah usia 65 tahun yaitu sebanyak 6 orang $(54,5 \%)$. Karakteristik responden berdasarkan jenis kelamin menunjukkan bahwa dari 12 orang responden terdapat 5 orang laki-laki $(45,5 \%)$ dan perempuan sebanyak 6 orang $(54,5 \%)$. Berdasarkan pendidikan terakhir menunjukkan bahwa dari 11 sebagian besar pendidikan terakhir dari responden adalah Strata 1 yaitu sebanyak 9 orang $(81,8 \%)$.

Berdasarkan karakteristik status pernikahan responden menunjukkan bahwa dari 11 responden semua responden berstatus menikah yaitu sebanyak 11 orang $(100,0 \%)$. Berdasarkan sumber penghasilan responden, pada tabel 1 menunjukkan bahwa dari 11 responden sumber penghasilannya berasal dari dana pensiun yaitu sebanyak 11 orang $(100,0 \%)$. Hal ini menunjukkan bahwa semua responden telah memasuki masa pensiun. Berdasarkan pekerjaan terakhir menunjukkan bahwa dari 11 orang responden pekerjaan terbanyak yang menjadi responden pada penelitian ini adalah PNS yaitu sebanyak 10 orang $(90,9$ $\%)$.

\section{2) Karakteristik Status Harga Diri Lansia Sebelum Dan Setelah Intervensi.}

\section{Tabel 2.Distribusi Frekuensi Reponden Berdasarkan Harga Diri Sebelum Pemberian Reminiscence group therapy}

\begin{tabular}{ccc}
\hline $\begin{array}{c}\text { Status Harga } \\
\text { Diri }\end{array}$ & $\begin{array}{c}\text { Jumlah (n) } \\
\text { Presentase (\%) }\end{array}$ & Total \\
\cline { 1 - 1 } $\begin{array}{ccc}\text { Harga Diri } \\
\text { Rendah }\end{array}$ & 7 & 63,6 \\
\cline { 1 - 1 } $\begin{array}{c}\text { Harga Diri } \\
\text { Normal }\end{array}$ & 4 & 36,4 \\
\cline { 1 - 1 } Total & $\mathbf{1 1}$ & $\mathbf{1 0 0}$ \\
\hline
\end{tabular}


Tabl 2munjukkan bahwa dari 11 responden, status harga diri lansia post power syndrome sebelum intervensi sebagian besar beraa pada kategori harga diri rendah yaitu sebanyak 7 responden $(66,6 \%)$. Sedangkan status harga diri lansia post power syndrome yang termasuk dalam kategori normal yaitu sebanyak 4 responden (33,3\%). Hal ini membuktikan bahwa sebelum dilakukan reminiscence group therapy sebagian besar harga diri lansia berada pada kategori harga diri rendah yang sesuai dengan kriteria yang ditetapkan dalam instrumen Rosenberg self esteem.

Tabel 3 Distribusi Frekuensi Responden Berdasarkan Status Harga Diri Setelah Pemberian Reminiscence group therapy

\begin{tabular}{|c|c|c|}
\hline \multirow{2}{*}{$\begin{array}{l}\text { Status } \\
\text { Harga } \\
\text { Diri }\end{array}$} & \multicolumn{2}{|c|}{ Total } \\
\hline & Jumlah (n) & Presentase (\%) \\
\hline $\begin{array}{c}\text { Harga Diri } \\
\text { Normal }\end{array}$ & 11 & 91,7 \\
\hline Total & 11 & 91,7 \\
\hline
\end{tabular}

Berdasarkan tabel 3 menunjukkan bahwa setelah dilakukan reminiscence group therapy responden yang semula berada pada kategori harga diri rendah mengalami perubahan harga diri serta responden yang semula berada pada kategori harga diri normal juga ikut mengalami peningkatan harga diri dengan hasil 11 responden berada pada kategori harga diri normal. Hal ini menunjukkan bahwa setelah dilakukan reminiscence group therapy, terjadi perubahan status harga diri pada lansia yang menandakan bahwa terdapat perubahan positif pada penilaian diri lansia.

\section{b. Analisa Bivariat}

Tabel 4.4 Pengaruh Reminiscence group therapy Terhadap Harga Diri Pada Lansia

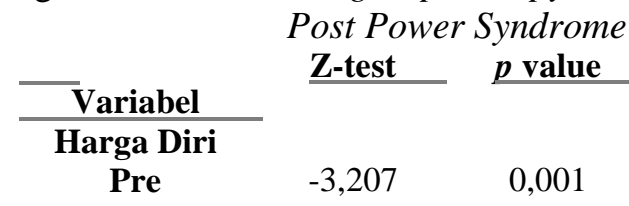

\section{Harga Diri Post}

Sumber : Data Primer, 2018.

Berdasarkan hasil Uji Wilcoxon Test diperoleh nilai $\mathrm{p}$ value sebesar 0,001 . Secara statistik, jika nilai $\mathrm{p}<0,05$ maka Ha diterima. Oleh karena itu, berdasarkan hasil analisis tersebut dapat disimpulkan bahwa terdapat pengaruh reminiscence group therapy terhadap status harga diri pada lansia post power syndrome di Wilayah Kerja Puskesmas Samata

\section{PEMBAHASAN}

Hasil menunjukkan bahwa terdapat pengaruh reminiscence group therapy terhadap status harga diri lansia post power syndrome. Sebelum dilakukan pemberian reminiscence group therapy, status harga diri lansia tampak bervariasi. Hasil penelitian menunjukkan bahwa sebanyak 7 orang responden berada pada kategori harga diri rendah dan 4 responden berada pada kategori 
harga diri normal. Berdasarkan hasil observasi dan wawancara dengan responden, hal inidisebabkan lansia yang telah pensiun menganggap bahwa disaat dia sudah tidak bekerja maka dia menganggap bahwa kualitas dirinya telah gagal karena diusianya yang saat ini semakin bertambah dia sudah tidak bisa memberikan yang terbaik untuk keluarganya sehingga rasa puas dan rasa berarti pada dirinya sudah mulai berkurang. Sedangkan untuk responden dengan harga diri normal menganggap bahwa meskipun responden menerima kondisinya yang sudah tidak bekerja lagi, namun mereka terkadang beranggapan dan merasa bahwa orang-orang disekitarnya sudah tidak menunjukkan penghargaan seperti disaat mereka bekerja dulu sehingga hal ini yang membuat responden merasa kurang puas dengan dirinya disaat telah pensiun.

Peneliti berasumsi bahwa usia lanjut merupakan masa pensiun yang ditandai dengan perubahan fisik,psikologis dan sosial lansia yang semakin melemah dan berarti bahwa produktivitas lansia akan semakin menurun hal ini yang mempengaruhi cara pandang lansia terhadap konsep dirinya yang akan semakin menurun. Hal ini sejalan dengan pendapat yang dikemukakan oleh Berk (2012) yang mengatakan bahwa masa pensiun melibatkan pelepasan peran yang menjadi bagian penting dari identitas dan penghargaan diri yang biasanya diasumsikan sebagai proses yang menimbulkan stress. Kehilangan peran atau merasa ditolak dapat mengarahkan pada penurunan self image yang bahkan bisa berakibat kehilangan harga diri ( Nurhayati, 2015).

Setelah diberikan reminiscence group therapy selama 9 kali pertemuan terjadi perubahan status harga diri lansia dari harga diri rendah setelah terapi berada pada kategori status harga diri normal. Hal ini berkaitan dengan penelitian yang dilakukan oleh Syarniah (2010) yang mengatakan bahwa Harga diri rendah pada lansia yang mendapat terapi reminiscence group therapy dengan mengalami peningkatan harga diri yang bermakna setelah terapi dilakukan. Karena berdasarkan pernyataan lansia terkait manfaat yang dapat dirasakan setelah terapi dilakukan adalah lansia lebih bisa menemukan kelebihan yang ada pada dirinya, responden lebih merasa percaya diri serta terbangun perasaan dan fikiran positif di dalam dirinya untuk tetap bangga terhadap apa yang telah dimiliki saat ini Agarwal

menyatakan bahwa cara untuk membangun kembali harga diri pada lansia adalah dengan cara memotivasi lansia untuk bertemu dengan teman-temannya dan berbagi cerita masa lalunya. Pernyataan ini sesuai dengan reminiscence group therapy yang dilakukan secara berkelompok, dimana lansia dapat membagi pengalaman masa lalunya dengan sesama lansia. Penurunan harga diri lansia dalam hasil penelitian ini memperkuat teori yangbahwa reminiscence group therapy bertujuan untuk meningkatkan harga diri. Komunikasi yang dilakukan oleh lansia dengan lansia yang lain di dalam suatu kelompok dapat menjadi salah satu aspek yang dapat meningkatkan rasa bangga pada diri lansia serta lansia juga dapat mendapat dukungan terkait kemampuannya tersebut dari lansia yang lain. Hal inilah yang dapat meningkatkan perasaan bangga dan berharga pada diri lansia, sehingga harga diri lansia dapat group therapy terhadap status harga diri lansia post power syndrome di wilayah kerja puskesmas samata Penelitian ini menunjukkan adanya perbedaan yang signifikan status harga diri lansia sebelum dan setelah reminiscence group therapy. Sebelum pemberian therapy, terdapat 7 responden dengan harga diri rendah dan 4 dengan status harga diri normal .Sedangkan setelah dilakuakn terapi, 11 orang responden mengalami perubahan status harga diri menjadi harga diri normal. Dalam proses reminiscence group therapy yang dilakukan secara berkelompok akan terjadi kegiatan eksplorasi pengalaman positif dari setiap anggota kelompok dan pemberian tanggapan dari anggota kelompok lain. Dalam kegiatan diskusi pada terapi kelompok reminiscence ini lansia dimotivasi untuk menyampaikan hal positif yang pernah dialaminya baik secara mandiri maupun bersama keluarga dan orang lain. Eksplorasi aspek positif yang pernah dialami lansia pada masa lalu ini merupakan salah satu upaya untuk meningkatkan perasaan berharga bagi lansia dan terapis memberikan penguatan atas perasaan bangga dan berharga 
yang dimiliki oleh lansia. Peneliti berasumsi bahwa dengan bercerita tentang pengalaman masa lalu maka secara tidak langsung terapis membantu menstimulus serta mengajak lansia untuk mengeksplorasi perasaan dan pengalamanpengalaman berharga dalam kehidupannya yang bermakna sehingga terwujud perasaan bangga dan individu mampu menumbuhkan penguatan perasaan terhadap nilai dirinya sendiri. Hal ini sejalan dengan pernyataan Stuart (2016) yang mengungkapkan bahwa terapi reminiscence digunakan untuk membantu individu mencapai integritas,meningkatkan harga diri dan menstimulasi individu untuk berfikir tentang dirinya sendiri.

Harga diri dalam bahasa arab disebut 'Izzah'. Harga diri berkaitan dengan kemampuan individu utnuk menilai diri sendiri. Aspek evaluatif dari konsep diri yangg dimiliki oleh seseorang adalah harga diri. Al- Qur'an mengajarkan bahwa harga diri dari kualitas terbaik seorang mukmin adalah taqwa kepada Allah s.w.t ( Purwakina, 2016). Sebagaimana dalam Q.S. AliImran: 139:

Terjemahnya :

"Janganlah kamu bersikap lemah, dan janganlah (pula) kamu bersedih hati, padahal kamulah orang-orang yang paling tinggi (derajatnya), jika kamu orang- orang yang beriman (Kemenag, 2017).

Dalam ayat ini islam menganjurkan umatnya agar tidak merasa rendah diri dengan orang lain, tetapi tidak boleh merasa lebih tinggi dari orang lain. Orang yang memiliki taqwa yang tinggi maka tinggi pula derajatnya disisi Allah s.w.t.orang yang memiliki harga diri yang tinggi mata Allah adalah orang yang bertaqwa, yaitu mereka yang selalu menjalankan perintah Allah s.w.t dan manjauhi larangan-Nya, melakukan kebaikan dan selalu menjauhi perbuatan yang dapat merugikan dirinya dan orang disekitarnya.

Melalui reminiscence group therapy secara tidak langsung memberikan kesempatan pada lansia untuk berbagi terkait pengalamannya kepada anggota kelompok yang lain, mampu meningkatkan komunikasi serta sosialisasi di dalam kelompok sehingga tercipta suasana yang harmonis dan memberikan efek relaksasi.
Peneliti mengevaluasi beberapa responden mengenai reminiscence group therapy dan menurut lansia yang menjadi responden, terapi ini membuat lansia lebih aktif dan lebih terbuka untuk bercerita tentang pengalaman serta halhal yang berarti dalam hidupnya sehingga membuat dirinya lebih bisa menerima keadaan serta lebih bersyukur terhadap apa yang telah di miliki saat ini. Perawat memiliki peran yang sangat penting terkhusus dalam memberikan asuhan keperawatan yang terkait dengan kebutuhan dasar manusia serta peran sebagai edukator dalam meningkatkan pengetahuan tentang status kesehatan individu. Setelah dilakukan penelitian ini, diharapkan lansia bisa lebih dapat terbuka dalam menyampaikan halhal yang dialaminya saat ini dan bisa lebih menerima keadaan serta dapat lebih bersemangat dalam melakukan aktivitas seharihari

\section{REFERENSI}

1. Al-Qur'an dan Terjemahannya. Kementerian Agama RI.

2. Arikunto, Suharsimi. 2010. Prosedur Penelitian Suatu Pendekatan Praktik. Jakarta : PT Rineka Cipta.

3. Dinsi, V, Setiati, E., \& Yuliasari, E. 2006. Ketika Pensiun Tiba. Jakarta : Wijayata Media Utama.

4. Ghufron, M Nur \& Risnawati, R. 2011.Teori Teori Psikologi. Yogyakarta: AR- Ruzz Media

5. Handayani,Y.2008. Post Power Syndrome pada Pegawai Negeri Sipil yang Mengalami Masa Pensiun.

6. Hardimansyah. 2014. PengaruhTerapi Reminiscence (Mengenang Masa Lalu yang Menyenangkan) Terhadap Depresi pada Lansia di Unit Rehabilitasi Sosial Pucang Gading Semarang

7. https://www.wwnorton.com/college/psych /psychsci/media/rosenberg.htm diakses pada tanggal 05 Agustus 2018 . 


\section{JOURNAL OF ISLAMIC \\ NURSING}

8. Elizabeth B. 2009. Psikologi Perkembangan Suatu Pendekatan Sepanjang Rentan Kehidupan. Jakarta: Erlangga

9. Hastuti, D. (2016). strategi pengembangan harga diri anak usia dini, 2. Retrievedfrom journal.uad.ac.id/index.php/JPSD/ article/download/5486/pdf_22

10.Ismalinda, W., Nauli, F. A., \& Dewi, A. P. (2016). Hubungan Keberadaan Pasangan Hidup Dengan HargabDiri Pada Lansia. Retrieved from https://repository.unri.ac.id/xmlui/bitstream/ handle/123456789/4457/MANUSCRIPT.pdf ?sequence $=1$

11.Kartono. 2014. Hygiene Mental . Bandung :Mandar Maju

12.Keliat,Budi Anna. 2014. Keperawatan Jiwa: Terapi Aktivitas Kelompok Edisi 2. Jakarta: EGC.

13.Kementerian Kesehatan RI. 2017. Analisis lansia di Indonesia.Pusat data dan Informasi.
14. Muhith dan Siyoto. 2016. Pendidikan Keperawatan Gerontik. Yogyakarta :Penerbit ANDI.

15.Narullita, D. (2017). Faktor-Faktor Yang Mempengaruhi Harga Diri, 2(October), 354-361.

16. Retrieved from ejournal.kopertis10.or.id/index. php/endurance/article/.../751.

17. Nofita, Effy.2011. Post Power Syndrome in Retired Manager Women

18. Notoatmodjo,soekidjo. 2012. Metodologi Penelitian Kesehatan. Jakarta : PT Renika Cipta.

19. Nugroho ,wahyudi. 2008. Keperawatan Gerontik dan Geriatrik, Ed.3.Jakarta: EGC.

20.Nurhayati, Istiqomah, Indriana, Yeniar. 2015. Harga Diri dan Kecenderungan Post Power Syndrome Pada Pensiunan Pegawai Negeri Sipil Anggota PWRI Cabagn Kota Cirebon. 